\title{
Sleepless in Seattle... the International Cancer Education Conference
}

\author{
Arthur M. Michalek
}

Published online: 15 October 2013

(C) Springer Science+Business Media New York 2013

Sleepless in Seattle [1] was not only a highly successful romantic comedy film (1993) but also the phrase that best captures the spirit of the recently completed International Cancer Education Conference co-organized by the American Association for Cancer Education (AACE), the Cancer Patient Education Network (CPEN), and the European Association for Cancer Education (EACE). It was a meeting filled with activity, engaging conversation, and even some sightseeing, leaving participants a bit bleary eyed by the end of the week. In the movie Sam Baldwin moves to Seattle with his young son to start a new life after his wife dies from cancer. Like aspects of the movie, we too were focused on living with cancer. A myriad of presentations were proffered in a variety of settings all focused on educational aspects of cancer. Many "firsts" have occurred at the annual meeting. This year was no exception in that it was our first "green" meeting. No book of abstracts was presented to meeting participants, but all were referred to the conference website (http://www.aaceonline.com/2013/ program.shtml) to both view the conference sessions and to access the abstracts of individual presentations. This change allowed for additional opportunities for both pre- and postconference learning. Kudos to the organizers!

The tone of the meeting was set by Dr. Mary Gospodarowicz, President of the UICC, who opened the meetings by giving the prestigious Samuel C. Harvey lecture. Her talk focused on global cancer control and global access to quality cancer care. She underscored the gravity of the cancer problem by pointing out that cancer deaths will increase by $20 \%$ in high-income countries and $60 \%$ in low- and middle-income countries. This is most certainly a call to arms given that one third to one half of cancer deaths are preventable. She referenced the work of Frenk et al. [2] who clearly define the problem and argue for a

A. M. Michalek ( $\varangle)$

D'Youville College, Buffalo, NY, USA

e-mail: jceditor1@gmail.com transformation of health education. They recognize the need to develop a global workforce and propose three core areas in which to generate "knowledge-related global public goods." These areas encompass metrics on professional education; evaluation and communication of what works, what doesn't and why; and research required for continuous improvement. These set forth clear guidelines for future programs. We, therefore, have a Herculean task before us that can only be accomplished through our mutual and concerted works.

Vic Strecher, $\mathrm{PhD}$, provided a stimulating and thoughtprovoking presentation on media and innovation in which he related his "epiphany." Frustrated that the field had hit a wall in terms of changing behavior, he was in search of a way to change thinking about health behaviors. His awakening resulted in a change of message and vehicle. He spoke to us of the importance of attaining positive health behaviors, of having a purpose in life, and of "SPACE" (sleep, presence, activity, creativity, and eating well). His muse and messenger throughout the talk was an entertaining and sage dung beetle... that's correct - a dung beetle holds the key to good health. You can read more of the adventures of this anime at dungbeetle.org. Enjoy the adventure.

Another engaging plenary was given by Anthony Back, $\mathrm{MD}$, on communicating with cancer patients. He provided some startling results concerning the mismatch between physician estimates of their patients' understanding and the patients' perceptions of the likelihood of cure. The discordance is alarming. Physicians significantly overestimate what the patients understand, and the patients overestimate their chances of cure. Dr. Back urged all to listen to their patients, to get to know their patients, and to assess what they want to know and how they want that information presented. My recap cannot begin to capture the excitement and helpfulness of his presentation. I would urge all to visit the NCI website to hear directly from Dr. Back (http://www.cancer.gov/cancertopics/coping/ prognosis/for-doctors-video). 
Dr. Beti Thompson provided the final plenary on Disparities. Dr. Thompson is Associate Program Head in the Cancer Prevention Program at the Fred Hutchinson Cancer Research Center and enjoys an international reputation in community research, tobacco research, and health disparities research. Disparities research is incredibly important in helping us to identify barriers so as to reduce cause-specific morbidity and mortality. This will become ever more important as the nation initiates reforms in health-care delivery aimed at optimizing access and outcomes. Dr. Thompson has conducted some extremely interesting work in the areas of communication among Latina women concerning breast cancer. Lack of communication results in Latina women not understanding if there is a problem or if they need to follow up with their doctor. Her research has also found that Latina women experience greater distress after receiving abnormal screening results compared to white women, and this can further exacerbate compliance issues.

The annual meeting also presented us with one more opportunity to honor our outgoing editor in chief. At the meeting, Dr. O'Donnell was presented with a gift of appreciation from the association, as well as something less tangible, but more lasting, and that was the naming of the "Joseph F. O'Donnell Early Career Investigator Award" for travel to future meetings. Dr. O'Donnell is a long-standing member of the AACE and has held numerous positions within the organization. As the award states, "Joe is known as a man of compassion, insatiable curiosity, and wisdom." Dr. O'Donnell first came in contact with the AACE during his fellowship training. This experience instilled in him a lifelong commitment to cancer education and passing along the mentorship he received to other young investigators. I would urge those early in their careers to keep an eye on the AACE website and apply for this prestigious award. The recipient will receive $\$ 3,000$ towards travel to next year's meeting in Clearwater, Florida, next October.

Also held in conjunction with this meeting was the annual JCE editorial board meeting where we learned, thanks to all the authors and reviewers, that we enjoyed another successful year. A few highlights include increased impact factor, decreased time from submission to decision, increased quality, and it is profitable. We owe a debt of gratitude to the Springer group, led by Ky'esha Hammond and Carmina Jimenez. Speaking of reviewers... we can always use more. Please contact me if you would like to review for the JCE.

And I shall conclude this editorial as Dr. Gospodarowicz concluded her talk with a quote from Moliere, "It is not only what we do, but also what we do not do, for which we are accountable." Let us continue to move forward! Be well.

\section{References}

1. TriStar Pictures (producer) and Ephron N (director) (1993) Sleepless in Seattle. Foster, Gary, Producer; Ephron, Nora, Director; TriStar Pictures

2. Frenk J, Chen L, Bhutta ZA, Cohen J, Crisp N, Evans T, Fineberg H, Garcia P, Ke Y, Kelley P, Kistnasamy B, Meleis A, Naylor D, PablosMartinez A, Reddy S, Scrimshaw S, Sepulveda J, Serwassa D, Zurayk H (2010) Health professionals for a new century: transforming education to strengthen health systems in an interdependent world. Lancet 376:1923-1958 